\title{
The long and short views of equity in education: Steady progress or "whack-a-mole"?
}

\author{
Stephen Roche ${ }^{1}$
}

Published online: 16 September 2015

(C) Springer Science+Business Media Dordrecht and UNESCO Institute for Lifelong Learning 2015

Arguably, the greatest flaw of Western culture is its individualism: the burning desire of each person to leave their indelible mark. Yet this same factor, probably more than any other, has also fuelled exploration, innovation and technological progress. It might best be described as a form of myopia, an over-identification with the achievements and failures of the present. Whereas the Native American Iroquois people famously sought to consider in all major decisions the impact their actions would have on seven future generations, the most powerful decision makers of today rarely look beyond the next election, or even the next quarterly report.

There is a risk of allowing a similar myopia to obscure our vision for education and learning. Governments are notoriously fond of five-year plans, just as international organisations such as the United Nations are attached to their fifteen-year targets. We have just reached the end of one such cycle - the Millennium Development Goals (MDGs). What was launched with a bang was retired with a whimper, despite the fact that many of the results are rather impressive (albeit falling short of the highly ambitious targets). The progress made in relation to the first element of the educational target - universal primary enrolment - has been quite astonishing, especially in Africa, where need was (and remains) greatest. The most recent Education for All (EFA) Global Monitoring Report states that "primary adjusted net enrolment ratios improved significantly, rising at least 20 percentage points from 1999 to 2012 in 17 countries, 11 of which were from sub-Saharan Africa" (UNESCO 2015, p. 75). Even if we allow that much remains to be done, a 20 per cent increase in just 13 years in a region with so many political and economic challenges is quite remarkable.

The authors of our first article in this issue - Bénédicte Gastineau, Norbert Kpadonou, Valérie Delaunay, Eve Senan Assogba and Josette Gnélé - acknowledge

Stephen Roche

s.roche@unesco.org

1 UNESCO Institute for Lifelong Learning, Hamburg, Germany 
the achievements of the MDG and EFA processes, but forego celebration in favour of a sober analysis of what the changed primary-education landscape in sub-Saharan Africa actually means in relation to equality of opportunity. Their article (in French), entitled "Inégalités scolaires à Cotonou (Bénin): rôle croissant de l'encadrement familial à la recherche d'une éducation de qualité", begins with a thorough literature review that examines the extent to which universal primary enrolment has been implemented in the region. Applying data gathered in a 2012 socio-economic survey, they then narrow their focus to Cotonou, the economic capital of Benin and a city representative of many in the region. During the period 2003-2012 Cotonou has seen remarkable improvement in several key indicators of primary education: gross enrolment increased from 88 per cent to 109 per cent, with the rate of enrolment of girls considerably exceeding that of boys, and the pupilteacher ratio plummeting from 53 to 37 . These figures compare favourably with those of many industrialised countries. However, certain other figures from the same survey raise cause for concern: the percentage of children enrolling in public versus private schools has fallen from 67 to 50 , and the percentage of qualified teachers in public schools from 73 to 39 .

In analysing these figures, the authors reveal a situation whereby the solution to one problem has begotten another. As African countries move towards the model of universal primary education that has existed in other regions for some generations, they encounter many of the same problems that beset countries with a longer tradition of universal enrolment. To cope with the rapid growth of student enrolment, the state hired many young teachers, often without initial training and on precarious employment contracts. The consequence has been a drop in quality, as a result of which many parents with the means to do so opt to educate their children privately or to augment their schooling with private tutoring. The authors express this situation succinctly: "it seems likely that the educational inequities have merely shifted from the exterior to the interior of the school system" (il est probable que les inégalités éducatives se soient déplacées de l'extérieur vers l'intérieur du système scolaire). When a large majority of children attend school, inequity is no longer expressed in simple binary terms of "in" or "out". Rather, a more complex set of factors prevail, foremost among which are the educational and socio-economic status of parents. The authors' findings raise the spectre of the unsolvable problem: apparently defeated, it re-emerges in another form, a bit like the fairground game of "whack-a-mole".

But this, in itself, is probably a myopic view. One can easily argue that a flawed and inequitable school system is far preferable to one of higher quality from which a majority or large minority are excluded; it surely represents progress. Yet, the value of higher enrolment diminishes greatly if children - especially those of disadvantaged families - fail to stay in school. A recent study involving a sample of 5 million children enrolled in Grade 1 across six sub-Saharan countries (Burkina Faso, Ethiopia, Mali, Niger, Senegal and Chad), revealed that only 57 per cent successfully made it to Grade 6 (Easton and Cobb 2013). The author of our second item, Ibrahima Bah-Lalya, considers the role that religious schools can play in meeting the needs of students who have dropped out of formal schooling, usually due to economic, but also for cultural and religious reasons. He draws upon existing 
literature, data compiled by educational systems, and a study conducted in 2013 by the Association for the Development of Education in Africa (ADEA) in four West African countries (Burkina Faso, Mali, Mauritania and Senegal).

Entitled "Koranic Education Centres: A viable educational alternative for the disadvantaged learner in Sahel Africa?", this research note asks whether the two education systems that co-exist across most of the Sahel-Saharan region - Koranic Education Centres (KECs) and formal schools - might collaborate and work in synergy with each other. The author offers several good reasons why this approach might work: an extensive network of largely self-funded KECs already exists (there are 40,000 in Niger alone); the highest rates of dropout in West Africa are found in the most traditional Islamic communities; and these communities are more likely to accept education, especially for girls, from a religious school. Drawing on the findings of the ADEA study, the author considers two approaches to collaboration where modern, secular education is incorporated into the KECs, or the KECs are mainstreamed to the formal apparatus. He goes on to enumerate 11 key challenges that must be addressed if KECs are to become a viable alternative to formal schooling. This research note is intended as a prelude to more substantive research currently being conducted by ADEA into ways of combining formal "modern" and informal "Koranic" schooling.

From school dropouts in West Africa, we switch our focus to another group of traditionally disadvantaged learners - indigenous communities in Brazil - and to another form of alternative education that has emerged to complement and even replace the mainstream school system. In their article entitled "Exploring the new challenges for indigenous education in Brazil: Some lessons from Ticuna schools", Alex Guilherme and Édison Hüttner provide a comprehensive case study of the schools developed for and by the indigenous Ticuna people of north-eastern Brazil. After first surveying the general conditions of education for indigenous people in Brazil, and the emergence of indigenous schools (of which there are now more than $2,000)$ to replace the state and missionary schools that hitherto dominated, the authors describe an approach to education that seamlessly blends the formal and informal. Noting that indigenous peoples do not recognise a dichotomy of "culture" and "nature", they reveal similar fluidity between study and play, teachers and shamans, animals and humans, belief and knowledge, science and art, school and community. Whereas the schools founded by Christian missionaries and later by the state attempted to transform indigenous people into "good Christians" or "good Brazilians", either coercing or luring them away from their own language and traditions, the indigenous-led schools that have emerged in the last thirty years play a pivotal role in protecting these traditions. Whereas classrooms, during the "integrationist" period, witnessed the suppression of indigenous tradition and language in favour of their purportedly superior "Western" counterparts, they are now in the vanguard of the revival of those same traditions: "in many villages the classroom is the main place of study [of indigenous knowledge], since the forests surrounding them have disappeared and the community elders no longer recount their old stories and myths."

The authors conclude by considering not only the future of indigenous education, but also the lessons it may hold for non-indigenous communities: "we have much to 
learn from indigenous schools and their pluralistic, diverse and inter-ethnic foundations, if we are to make our societies truly pluralistic". Indigenous schools therefore provide a non-invasive window to observe and learn from indigenous peoples, a process that was impossible under the previous integrationist school system. The authors allow that certain elements of mainstream education, particularly health education, must also be included in the curriculum of indigenous schools: "health education remains of pivotal importance for indigenous groups, given that their life expectancy is generally much lower than that of mainstream society; but it must be done with the community, taking account of their context and traditions, otherwise we risk going back to a recent past when mainstream society imposed a view of the world on indigenous groups which inflicted much damage on them."

Efforts to improve quality in public schools and thereby counteract the kinds of systemic inequalities described in the first article of this issue invariably run into issues of cost. Private schools can often afford to invest in the most modern facilities and technologies, and attract the most highly qualified teachers; public schools generally cannot. The article by Matthew Wennersten, Zubeeda Banu Quraishy and Malathi Velamuri evaluates a project that set out to tackle one of the above factors; the technology gap between private and public schools. Entitled "Improving student learning via mobile phone video content: Evidence from the BridgeIT India project", this paper presents a thorough and comprehensive evaluation - based on both qualitative and quantitative data - of an ICT-based learning programme administered through mobile phones in public schools. Funded by mobile phone manufacturer Nokia and the Pearson Foundation, BridgeIT has so far been applied in Bangladesh, Chile, Colombia, Haiti, India, Indonesia, Nigeria, the Philippines, South Africa and Tanzania. The authors describe the intervention in India, and discuss the possible implications of the evidence obtained from the evaluation.

The core concept behind BridgeIT was to supply educational videos from a Cloud-based database to teachers through specially provided mobile phones. Teachers were notified of the availability of new videos via text messages (SMS), which they downloaded onto their phones using an open-source application and showed, with suggested activities, to students on a TV or projector screen using a TV-out cable. Specialised training and helpdesk support were also provided to teachers. The great advantage of this approach compared to the more common computer-based interventions (such as One Laptop per Child) is the existing familiarity with mobile technology, the low cost per teacher (less than USD 700), the scalability, and particularly in the case of India, the high mobile coverage and reception quality (according to telecom subscription data, India had 952 million mobile subscribers as of January 2015; TRAI 2015). Originally piloted at 34 schools in the states of Andhra Pradesh and Tamil Nadu in the 2011-2012 school year, the project was expanded to cover 86 schools in the two states the following year. Preand post-intervention tests were administered in the test schools as well as in control schools. These were modelled on the standardised tests that supply data to India's Annual Status of Education Reports (ASER); students were asked to answer increasingly difficult questions based on grade-normed English and Science passages. 
In their evaluation of this project, the authors found that the test scores of children who experienced the intervention improved by 0.36 standard deviations in English and 0.98 standard deviations in Science in Andhra Pradesh, relative to students in similar classrooms who did not experience the intervention. Differences between treatment and control schools in Tamil Nadu were less marked. BridgeIT worked especially well when implemented in conjunction with other targeted student preparatory programmes. In sum, the results indicate that it is possible to use mobile phones to produce a sizeable, positive and statistically significant effect across a large number of classrooms at a lower cost per student than similar past interventions were able to achieve.

Concerns about equity in education do not, of course, end in the classroom. Patterns of inequity in terms of educational opportunity and achievement established in childhood tend to persist into adulthood. Meanwhile, processes of globalisation and rapid technological change have induced policymakers and employers to pay greater attention to adult education, especially non-formal jobrelated learning. The primary focus of such policy has been to increase participation rates. As the authors of our fifth article - Elina Kilpi-Jakonen, Daniela Vono de Vilhena and Hans-Peter Blossfeld - argue, there are good reasons to be equally interested in the social inequalities in participation and to focus on the educational selectivity of participants.

The specific aim of their paper, entitled "Adult learning and social inequalities: Processes of equalisation or cumulative disadvantage?", is to examine crossnational patterns of social inequality in participation in formal and non-formal jobrelated adult learning, and the consequences of participation on individual labour market trajectories. The article draws on the results of 13 longitudinal country studies conducted as part of an international comparative study called $e d u$ Life, as well as two cross-sectional international comparative studies (the Adult Education Survey and the International Adult Literacy Survey). They show that higher participation rates do not necessarily lead to lower social/educational inequalities in participation, and that, despite wide variations in participation rates across countries, the mechanisms of social/educational inequality tend to be relatively similar across countries, in particular with regard to non-formal learning. The country studies also reveal that returns gained from participation in formal adult education take several years to fully materialise. The authors conclude that it is difficult to reduce social inequalities through adult learning and that participation in learning often conforms to a pattern of cumulative advantage, whereby those who are already better endowed also receive more. They recommend that policy makers place greater emphasis on making adult learning more accessible (in terms of entry requirements, affordability and motivation) to underrepresented groups, in particular those who are not intrinsically motivated (e.g., by the promise of increased wages or employment status) or have been disadvantaged educationally and on the labour market.

The final article in this issue turns to the issue of recognition, validation and accreditation of prior learning (RVA), which has been embraced by numerous international agencies, including UNESCO, OECD and the European Council, as an important component in the provision of meaningful adult education and lifelong 
learning opportunities. The underlying premise of RVA is that adult learners need not only to "catch up" on what they missed out on in formal schooling, but require recognition for the broad range of knowledge and skills they acquired outside of the classroom. It not only dignifies their choices and experiences, but offers a practical mechanism to "translate" competencies into "credits" that allow them to re-enter the formal education system without having to start at the last level attained. It also provides a similar pathway into the formal labour market. As such, it provides both an incentive to re-engage in education and a route to more stable and better-paid employment. Crucial to the implementation of RVA is the creation of so-called national (or regional) qualifications frameworks, which allow prior learning to be transparently and uniformly linked to equivalent qualifications and levels attained through the formal education and training system.

In their article entitled "Challenges in implementing national systems of competency validation with regard to adult learning professionals: Perspectives from Romania and India", Simona Lidia Sava and S. Y. Shah examine the specific issue of RVA for adult educators. One of the greatest challenges in adult education globally is a lack of qualified personnel. Where university programmes to train adult educators and opportunities for remuneration are few, programmes frequently rely on volunteers, who may or may not have received professional training. RVA can therefore play a vital role in professionalising the adult education sector through the recognition of skills acquired through practice and the identification of further training needs. This paper presents and analyses practitioners' experiences with a piloted portfolio tool (called ValidPack) designed to support the validation of pedagogic competencies of trainers in adult education. While the pilot study was carried out in 20 European and 2 non-European countries, the authors chose to compare feedback only from participants in Romania and India, two countries that are currently striving to implement RVA. The pilot study confirmed ValidPack's potential for use and adaptation to different national and regional contexts, both for countries with advanced systems and practices of RVA, and for those where such systems and practices are more limited.

\section{References}

Easton, P., \& Cobb, M. (2013). Social trajectories and literacy retention among West African school dropouts. The flip side of education for all. Paper presented at the Southeast regional conference of the Comparative and International Education Society. Tallahassee, FL: Florida State University.

TRAI (Telecom Regulatory Authority of India) (2015). Highlights of telecom subscription data as on 31st January 2015. Press Release No. 18/2015. New Delhi: TRAI. Retrieved 31 August 2015 from http:// www.trai.gov.in/WriteReadData/WhatsNew/Documents/PR-TSD-120315.pdf.

UNESCO (2015). Education for all 2000-2015: Achievements and challenges. EFA Global Monitoring Report 2015. Paris: UNESCO. 